DOI 10.37882/2223-2982.2021.07.17

\title{
ГЕНДЕРНЫЙ ТИП ЖЕНСКОЙ ЛИЧНОСТИ В РУССКОЙ И АНГЛИЙСКОЙ ЛИНГВОКУЛЬТУРАХ
}

\section{GENDER TYPE \\ OF FEMALE PERSONALITY IN RUSSIAN AND ENGLISH LINGUISTIC CULTURES}

\section{A. Kormiltseva}

Summary: The constantly changing modern reality requires from the humanities to search for new methods of analysis and interpretation of social transformations taking place in society. The study of the speech behavior of native speakers in this channel seems to be one of the tools with which it is possible to track the ongoing changes in society, since it is thanks to language that people are able to form their feelings, feelings and thoughts in verbal form and exchange them with each other. In connection with the need to take into account the factors affecting the speech behavior of native speakers, works appear in modern linguistics in which scientists attempt to systematically comprehend speech in conjunction with the biological gender of the speaker. In this article, the author has made an attempt at scientific analysis and critical understanding of the gender type of female personality in Russian and English linguistic cultures.

Keywords: gender personality type, female personality, Russian linguoculture, English linguoculture, linguistic characteristics.

\author{
Кормильцева Алевтина Леонидовна \\ К.филол.н., Елабужский институт Казанского \\ федерального университета г. Елабуга \\ kormilcevaa@mail.ru
}

Аннотация: Постоянно меняющаяся современная реальность требует от гуманитарных наук поиска новых методов анализа и интерпретации социальных трансформаций, происходящих в обществе. Исследование речевого поведения носителей языка в данном русле представляется одним из инструментов, с помощью которого можно отслеживать происходящие изменения в обществе, поскольку именно благодаря языку люди способны оформлять свои ощущения, чувства и мысли в словесную форму и обмениваться ими друг с другом. В связи с необходимостью учета факторов, влияющих на речевое поведение носителей языка, в современной лингвистике появляются работы, в которых ученые совершают попытки системного осмысления речи В совокупности с биологическим полом говорящего. В настоящей статье автором предпринята попытка научного анализа и критического осмысления гендерного типа женской личности в русской и английской лингвокультурах.

Ключевые слова: гендерный тип личности, женская личность, русская лингвокультура, английская лингвокультура, лингвистические характеристики.

лей языка, т.к. в ней сочетаются критические и гендерноориентированные методы анализа речи, что позволяет отнести ее к одной из первых попыток осмысления влияния гендерных характеристик говорящего на его речевое поведение.

Со временем понятие «гендер» начинает проникать во все гуманитарные науки - социологию, историю, психологию, языкознание, литературоведение, лингвистику и др. Данное направление вызывает большой интерес ученых ввиду своей сложности и новизны. С.В. Журавлева в исследовании гендерных факторов речи в английском языке объясняет причины, по которым лингвисты обращают внимание на биологический пол говорящего: «Характерной особенностью первого этапа становления гендерных исследований - биологического детерминизма - было признание факта, что физиологические, культурологические, поведенческие, интеллектуальные, а также отличия речевого поведения мужчины и женщины определяются биологическим полом». Автор утверждает, что ученые рассматривают половую принадлежность человека не только с биологической и физиологической точки зрения, но и с точки зрения психологических особенностей мужчины и женщины, которые оказывают 
влияние на выбор моделей речевого поведения представителей одной лингвокультурной среды [4, с. 62].

На начальном этапе становления гендерных исследований в языке мужское речевое поведение принималось за нормативное: «особое направление составляют мужские исследования (men studies), призванные дать ответ на вопросы, как конструируется обществом мужественность, какие типы мужественности существуют в данной культуре, в данное время, как это сказывается на поведении людей, каковы нормы и требования к мужчинам».

Однако маркеры женского речевого поведения, более оперативно реагирующие на социокультурные изменения, вскоре становятся предметом изучения многих специалистов (Т.В. Гомон, Е.И. Горошко, А.В. Кирилина, Р. Лакофф, В. Лабов, Е.Н. Малюга, Д. Таннен, В.Н. Телия, К. Тафель, М.В. Томская и др.).

В фокусе внимания этих специалистов концепт женщина, являющийся маркированным, отличающимся от нормы, эталон которой по традиции ассоциировался с мужчиной. Так, совершенно справедливо отмечается, что «...мужской род в английском языке традиционно считается признаком нормативности в употреблении как лексических, так и грамматических единиц, в то время как женские маркеры до недавнего времени находились на периферии исследовательского внимания».

Сегодня интерес к особенностям женского речевого поведения не ограничивается только изучением факторов, оказывающих влияние на речь представительниц женского пола, но распространяется на исследование социальных и культурных аспектов их речевого поведения. В фокусе внимания в наши дни оказываются те особенности женских речевых стратегий, которые отражают женский стиль общения и его прагматическую коммуникативную специфику.

Анализ женской речи достаточно подробно описывается в монографии Робин Лакофф «Язык и место женщины», где женский разговорный стиль бытового общения ассоциируется с более низким социальным уровнем. Автор приводит примеры женского речевого поведения в условиях бытового общения - уход за детьми, семейные ситуации, обсуждение модных тенденций и т.п., активно используется так называемая женская лексика (имена существительные с уменьшительными и ласкательными суффиксами, лексические единицы, обозначающие предметы детской гигиены, детского питания, наименования телевизионных программ для женской аудитории, названия фирм по производству модной женской одежды или косметики и т.п.) [8, с. 11].

На грамматическом уровне, по мнению автора, женская речь характеризуется частотным использованием вопросительных конструкций, среди которых особое место занимают TAG-questions (разделительные вопросы), которые смягчают тональность высказывания. Выделенные в монографии Робин Лакофф маркеры женского речевого поведения часто используются англоязычными драматургами при оформлении коммуникативных ситуаций с женскими персонажами.

Например, ZOE: I was half expecting you to drop to your knees and kiss the tarmac. You know, like the Pope. Aw, come on - you're not still in a huff? You are, aren't you? \3ОИ: Я noчти ожидал, что ты упадешь на колени и поцелуешь асфальт. Знаешь, как Папа. Да ладно тебе, ты же не в обиде? Да?

SELMA: Good. It sure is a beautiful day, isn't it? \СЕЛЬМА: Хорошо. Сегодня прекрасный день, не правда ли?

LIZ: Well that's just great, Alex. Now how about leaving? / ЛИз: Это просто здорово, Алекс! А теперь как насчет mого, чтобы уйти?

ALEX: And you would be. Liz. / АЛЕКC: А Вы должно быть, Лиз?

LIZ: How'd you know that? / ЛИз: Откуда Вы узнали?

ALEX: I don't know! / AЛЕКС: Не знаю!

LIZ: How did you know my name? / ЛИз: Откуда Вы узнали мое имя?

ALEX:Lucky guess, I guess. / АЛЕКС:Думаю, просто угадал.

Речевое поведение носителей языка формируется под воздействием общественных тенденций и стереотипов, которые структурируют гендерный социальный опыт индивида, когда ребенок с момента рождения усваивает, что значит быть мальчиком или девочкой, а впоследствии - мужчиной или женщиной, в этот момент происходит восприятие модели гендерного поведения, принятой в данном обществе. Итоговым выводом в работе авторитетного специалиста по гендерной тематике можно считать тезис об определяющей роли лингвокультурных и гендерных маркеров в условиях формирования адекватной коммуникации [1, с. 18].

Оформление реплик персонажей женского пола в современной англоязычной драматургии происходит при помощи обнаруженных исследователями маркеров. Наиболее очевидным маркером фемининных речевых портретов в рамках современного англоязычного драматургического дискурса является упоминание названий брендов, имен популярных актеров, певцов и названий фильмов. Например, CAROL: I like shopping at Walmart. They have low prices. I don't care if they are politically inconvenient / КЭРОЛ: Мне нравится делать покупки в «Walmart». У них низкие чены. Мне плевать, если они политически некорректны.

MOM: Well, you live and learn. My friend from my bridge club gave me the Mamma Mia DVD thinking that would cheer me up and actually it did. Normally I can't stand Meryl 
Streep but this was her best movie. She's so trashy she's absolutely brilliant. It's a three Kleenex Äick. And I got all these frickin' Abba songs in my head. (Pause) Look, I did a little amateur research on the internet, Nate. You don't need a damn PhD. / MAMA: Ну, век живи и учись. Мой друг из моего бридж-клуба подарил мне «Mamma Mia» DVD, думая, что это меня подбодрит, и это действительно так. Обычно я терпеть не могу Мерил Стрип, но это был ее лучший фильм. Она такая дрянная там, что просто великолепно. Это три салфетки «Клинекс». И у меня в голове все эти дурацкие песни АББА. Слушай, Нейт, я провела небольшое любительское расследование в Интернете. Не нужна тебе эта чертова докторская степень [6, с. 110].

VERONICA: Finally, they've succeeded in printing a picture that does justice to my remarkable features. Yves, we've got to find a moment in my schedule to stop at Tiffany's. I was told that the jeweler just received a new African collection of jewels. It's the new trend. / ВЕРОНИКА: Наконец-то им удалось напечатать фотографию, которая отражает мои замечательные особенности. Ив, нам нужно найти момент в моем расписании, чтобы остановиться у Тиффани. Мне сказали, что ювелир только что получил новую африканскую коллекцию драгоценностей. Это новый тренд.

LIZ: So what is this? Some sort of strange Charles Bronson/Freddie Krueger/Chucky Meets Jason/"I'm baaaaaaaaaaaac!" scenario! (Moher, 1991) / ЛИЗ: Так, и что это? Какой-то странный Чарльз Бронсон / Фредди Крюгер / Чаки встречает Джейсона / «Я вернулся!» сценарий!

MARGE: If you'd had to put up with what I've had to put up with over the years. When you gave me that first Mercedes, every time I drove it was, 'Here comes Queen of the $\mathrm{S}$ again.' Then I went and did all those courses. Macrame for the Boudoir. Cooking For Your Celebrity Guest. / МАРДЖ: Если бы тебе пришлось мириться с тем, с чем мне приходилось мириться годами. Когда ты подарил мне тот первый «Мерседес», каждый раз, когда я садилась за руль, я говорила: «А вот и снова королева S». Затем я ходила на эти курсы: «Макраме для будуара», «Готовим для нашего звездного гостя».

Ученые, исследующие гендерные маркеры речевого поведения, отмечают, что к фемининной лексике относятся: эмоционально окрашенные прилагательные, лексика, связанная с сугубо женским времяпрепровождением, смягчающие слова, языковые средства самозащиты - вводные слова, фразы-клише. Грамматическая составляющая мужского языка отражает упрощенные конструкции, насыщенные глаголами в активном залоге, при этом нередки отклонения от грамматических норм. Женщины, напротив, более внимательны к правильности речи, при этом часто используют усложненные оборотами грамматические конструкции, также они используют пассивные конструкции в целях избегания давления на собеседника [2, с. 48].

K маскулинным признакам речевого поведения по традиции относят: архаичный лексикон, редкие и диалектные слова, технические термины, сниженные лексические средства, профессиональный жаргон, что находит отражение в репликах мужских персонажей в пьесах современных английских драматургов. Речевое поведение женщин более эмоционально, ориентировано на диалог и сотрудничество; мужчины - более динамичны, независимы, вспыльчивы. Считается, что мужчинам свойственен «командный стиль», что предполагает акцент на собственные интересы, принятие рациональных и логически продуманных решений. Их речевое поведение нацелено на завоевание независимого статуса. Женщины, напротив, более уступчивы, способны принимать во внимание интересы других партнеров по общению. Для них характерно интуитивное поведение, ориентация на процесс, а не на цели.

При изучении гендерных особенностей речевого поведения необходимо опираться на многогранную и комплексную систему языка. Сложность детального описания речевого поведения коммуникантов при изучении гендерных параметров речевого поведения заключается в том, что необходимо учитывать все особенности языковой системы, к которым Леонович, Л.М. относит следующие:

1. категории действительного мира;

2. мыслительные категории, присущие логике и психологии человеческого познания;

3. прагматические факторы, то есть то, что связано с целенаправленным использованием языка в человеческой деятельности;

4. отношения между знаками - единицами языковой системы» [5, с. 185].

Современные исследования гендерных речевых характеристик происходят в рамках следующих теоретических направлений: теория дефицитности (объясняет различия в употреблении языка мужчинами и женщинами); теория доминирования (объясняет отражение гендерных различий в языке всеобщего патриархального порядка и трактует их с точки зрения проявления в языке мужских привилегий); теория различия (рассматривает гендерные различия как результат социализации и принадлежности женщин и мужчин разным, но равноправным субкультурам).

Ученые-гендерологи отмечают различную направленность мужской и женской речи: «В акте речевой коммуникации женщина, как правило, занимает подчиненную позицию, эмоциональна, ориентирована на диалог, в то время как мужчина более динамичен, активен, независим. Вследствие этого женская речь насыщена 
метафорами, эпитетами, сравнениями, экспрессивными прилагательными. Активность мужчин в речевых актах выражается в употреблении терминов, глаголов в активном залоге». В рамках нашего исследования маркеров речевого поведения персонажей мужского и женского пола в условиях современного драматургического дискурса внимание фокусируется на следующих проблемах:

1. динамика гендерных маркеров мужских и женских речевых портретов;

2. особенности мужского и женского речевого поведения, которые опираются на изучение концептов в гендерном аспекте;

3. статус коммуникантов мужского и женского пола в диалогах, раскрывающих содержание ядерных элементов когнитивно-прагматических аспектов общения персонажей, речевое поведение которых эксплицитно содержит отражает параметры одного из четырех вариантов английского языка.

Как показал обзор исторического формирования понятия гендер применительно к коммуникации, гендерная проблематика в науке о языке требует многостороннего исследования, включающего в себя согласованное со многими гуманитарными дисциплинами представление о развитии понятия гендер. Если в ранних трактовках понятие гендер либо игнорировалось вообще, либо использовалось не в полном объеме, то на последующих этапах развития науки это понятие дифференцируется. Например, в науке о языке появляется описание гендерных маркеров речевого поведения мужчин и женщин. Особое внимание исследователей фокусируется на изменениях национально-культурных нормативов гендерного речевого поведения в эпоху глобализации.

Интерес к субъективным факторам построения коммуникативных актов требует от лингвистов учета характеристик отдельной личности, к которым по традиции относятся биологические, психологические, культурологические и социально обусловленные параметры. По словам А.А. Харьковской субъективные факторы восприятия мира отражаются в языке, что вызывает необходимость изучать пути и способы реализации субъективных аспектов речевого поведения с учетом разнообразных составляющих языковой личности [11, с. 28].

Стратегии наименования произведения в большинстве случаев ориентированы на реализацию двух функций: информирующую и аттрактивную. В работе «Лингвосинергетический потенциал функциональной парадигмы названий произведений американского изобразительного искусства XX-XXI вВ.» Т.В. Ефремова и А.А. Харьковская выделяют следующие способы реализации функции воздействия: лексические (слова с эмотивной окраской, абстрактные слова, иностранные слова, окказиональная лексика), грамматические (повествовательные предложения с эмоционально-экспрессивной модальностью, повелительные предложения с эмоционально-экспрессивной модальностью и др.), стилистические (эпитеты, метафоры, оксюморон, стилистическая инверсия). С учетом этого обстоятельства в настоящем разделе осуществляется анализ основных способов привлечения внимания аудитории к названиям пьес, выполненных авторами мужского и женского пола.

Как показывают наши наблюдения, именно в XXI веке обнаруживается повышение интереса рядового человека к индивидуальному, субъективному восприятию реальности, чему в значительной степени способствует популяризация глобальной сети, которая дает возможность каждому пользователю выражать мнение по интересующей его теме, что отражается в авторском выборе названий для своих пьес.

Е.С. Савина указывает на два этапа включения интернет-пользователей в интернет-дискурс: этап аттрактивности и этап реакции. Следовательно, одним из основных условий популярности драматургического произведения современного искусства является аттрактивный потенциал, способный побудить реакцию пользователей интернет-пространства и придать огласку произведению, тем самым обеспечив его популярность. Конечно, несправедливо утверждать, что в условиях отсутствия Интернета автор освобождается от необходимости привлекать внимание к своим произведениям [9, с. 78].

Так, выборка номинативных единиц драматургических произведений, опубликованных англоязычными авторами мужского пола в период с 1985 по 2000 гг., в 76\% случаев носит информационный характер, что позволяет адекватно понять основную идею произведения или указывает на место действия сюжета: A Small Family Business / Маленький семейный бизнес, A Walk in the Woods / Прогулка в лесу, Black Widow / Черная вдова, The Celebrated/Oтпразднован, Papers / Бумаги, Love and Anger / Любови и злоба.

Авторы-драматурги женского пола, в свою очередь, чаще прибегают к стратегии привлечения внимания аудитории к своим произведениям посредством субъективной оценки сюжетной линии произведения, поэтому уже в начале 90-х гг. XX века в 82\% названий пьес женских авторов встречаются заглавия, содержащие единицы субъективной оценки, к которым можно отнести: личные и притяжательные местоимения первого лица (48\%): Ourselves Alone / Только мы, I Am Yours / Я твой (Judith Thompson, Canada, 1988), Welcome to My Planet / Добро пожаловать на мою планету, Tonight We Anchor in Twofold Bay / Вечером будем на причале Туфолд; повелительные предложения (23\%):Welcome to My Planet / Добро пожаловать на мою планету, Having Our Say: The Delany Sisters / Нам есть что сказать: сёстры Дилейни, Don't Just Stand There - Jiggle! / Чего стоишь? Танцуй!; меж- 
дометия (3\%): Hush! / Tcc!, Oh Brother, Mum's the World /O, братеи, мать-мuр.

Тенденция субъективной оценки окружающего мира активно продолжает развиваться и в XX1 веке, когда в названиях пьес драматургов женского пола помимо вышеперечисленных маркеров дополнительно используются: прилагательные в сравнительной степени (8\%): Better Than This / Получше, чем этот, Colder Than Here/ Там холоднее, Superior Donuts / Превосходный пончик, You Got Older / Ты становишься старше. [12, с. 126]

Авторы мужского пола, напротив, чаще придерживаются так называемых «объективных» способов вербализации при наименовании своих произведений. Одной из тактик привлечения внимания к своим произведениям является обращение к потенциальной публике, что подтверждается: частотным использованием местоимения уои, которое создает иллюзию непосредственного обращения автора к читателю (46\%): See U Next Tuesday / Увидимся во вторник, One Day All This Will Be Yours / Однажды все будет твоим, Burying Your Brother in the Pavement / Закопать твоего брата в асфальт, Nobody Loves You / Тебя никто не любит, The Ride of Your Life / Поездка твоей жизни; включением вопросительных и восклицательных предложений (14\%): The Goat, or Who Is Sylvia? / Коза, или кто такая Сильвия?, Are You Hарру? / Ты счастлива?, Cut! \Сяяо!, TONY! The Blair Musical / Тони Блэр! Мюзикл!.

Авторы-драматурги мужского пола также нередко пытаются воздействовать на потенциального читателя, прибегая к грубой и нецензурной лексике в названиях своих произведений (8\%): Lies, Damn Lies and Documentaries / Ложь, чертова ложь и документальный фильм, Howard Arselicker / Говард Арселикер, Witches \& Bitches Ведьмы и стервы, The Motherfucker With The Hat / Придурок в шляne, Bloody Bloody Andrew Jackson / Чертов Эндрю Джексон.

Примеры использования нецензурной лексики в названиях драматургических произведений авторов женского пола обнаружены у австралийских писательниц (3\%): Bitch Goddess / Богиня Cтерва, Shit / Дерьмо. Данный феномен характеризует особенности гендерного речевого поведения австралийского общества, указывая на стремление драматургов женского пола шокировать современного зрителя [7, с. 24].

Гендерные стратегии в номинации современных английских драматургических произведений также проявляются на графическом уровне: авторы женского пола склонны к использованию ассонанса при наименовании своих произведении (20\%): Topdog/Underdog / Победитель и проигравший, Yоu Fancy Yourself / Ты себя развлекаешь, Laws of War / Законы войны, в отличие от авторов-мужчин, в заглавиях их произведений чаще встречается аллитерация(17\%): Simply Selma / Просто Сельма, Wishing Well \ Желая добра; Moonlight and Magnolias / Лунный свет и магнолии, Baby Boomer Blues / Блюз Бейбибумера, The Garden of Granddaughters/ Сад внучек, Lofty Larceny / Лофти Ларсени.

Данная особенность женского и мужского речевого поведения русскоязычного общества отмечалась в работе И.И. Халеевой «О гендерных подходах к теории обучения языкам и культурам». Оперируя полученными данными, можно прийти к выводу о существовании стереотипных графических предпочтений представителями мужского и женского пола, которые актуальны для представителей мужского и женского пола в англоговорящих странах [10, с. 31].

Выявление трендов в наименовании драматургических произведений авторами мужского и женского пола «открывает занавес» когнитивных тактик гендерного речевого поведения англоязычного общества. Анализ показал, что авторы женского пола обычно поднимают вопросы личного характера и выносят их в заглавия своих произведений в отличие от авторов мужского пола, для которых важно субъективное восприятие потенциального реципиента. Таким образом, можно сделать вывод, что когнитивные стратегии драматургов-женщин нацелены на раскрытие собственных чувств и переживаний, в то время как приоритеты мужских стратегий заключаются в ориентации на чувства и эмоции читателя.

\section{ЛИТЕРАТУРА}

1. Васильева, И.Б. К вопросу о гендерной вариативности в языке / И.Б. Васильева // Функционирование лексических единиц и грамматических категорий в русском языке: материалы ежегодного научного семинара аспирантов. - Калининград: Изд-во КГУ, 2004. - С. 18.

2. Васильева, И.Г. Гендерные сходства в языке: новый аспект гендерных исследований / И.Г. Васильева // Филологические науки. Вопросы теории и практики. - Тамбов: Грамота, 2014. - № 11 (41). Ч. І. - С. 48.

3. Габец, А.А. Лингвистические маркеры эмотивности языковой личности: (на материале женских речевых характеристик героев романа Джека Керуака «The Town and The (ity») / А.А. Габец; // Семантика и прагматика дискурса: межвуз. сб. науч. ст. / под редакцией А.А. Харьковской Самара: Издательство «Самарский университет», 2010. - С. 37.

4. Ж Журавлева, С.В. Развитие английского женского дискурса как функциональной системы: (на материале англ. яз. XIX-XXI веков): дис... канд. филол. наук: 10.02.04 / С.В. Журавлева. Тула: Тульский гос. пед. ун. имени Л.Н. Толстого. - 2010. - С. 62. 
5. Леонович, Л.М. Ирония как маркер гендерного речевого поведения персонажей современного англоязычного драматургического дискурса / Л.М. Леонович, А.А. Харьковская // Вестник Самарского государственного университета. - 2016. - № 1. - С. 185.

6. Назина, О.В. Основные направления гендерных лингвистических исследований / О.В. Назина // Материалы II Междунар. науч-практ. конф. -Пенза-Махачкала-Ереван, 2011. - С. 110.

7. Полякова, Л.С. Понятие «Гендер» в лингвистическом описании / Л.С. Полякова // Актуальные проблемы филологии и педагогической лингвистики. 2009. №11. - C. 24.

8. Пономаренко Е.В. Риторическое воздействие как фактор межнационального делового общения / Е.В. Пономаренко, А.А. Харьковская // Язык и коммуникация в современном поликультурном социуме: сб. науч. тр. -М., 2014. - С. 11.

9. Савина, Е.С. Гендерные особенности мелиоративных речевых актов в современном английском языке / Е.С. Савина // Известия Самарского научного центра Российской академии наук. - Самара, 2009. - Т. 11,4 (3). - С. 78.

10. Халеева, И.И. 0 гендерных подходах к теории обучения языкам и культурам / И.И. Халеева// Известия Российской академии образования. - 2000 -№1. - С. 31.

11. Харьковская А.А. Гендерные аспекты речевого поведения персонажей в романах Т. Парсонса «Man and Boy» и «Man and Wife» / А.A. Харьковская, С.В. Штепо // Всерос. науч.-практ. конф. «Филологические чтения: текст в межкультурном пространстве» 29 октября 2010г. - Оренбург. - С. 28.

12. Царева, Е.В. Женский дискурс и женские образы в современной литературе Великобритании / Е.В. Царева // Гендер: язык, культура, коммуникация: материалы III Междунар. конф. - М.: Московский государственный лингвистический университет, 2003. - С. 126.

( ) Кормильцева Алевтина Леонидовна (kormilcevaа@mail.ru).

Журнал «Современная наука: актуальные проблемы теории и практики»

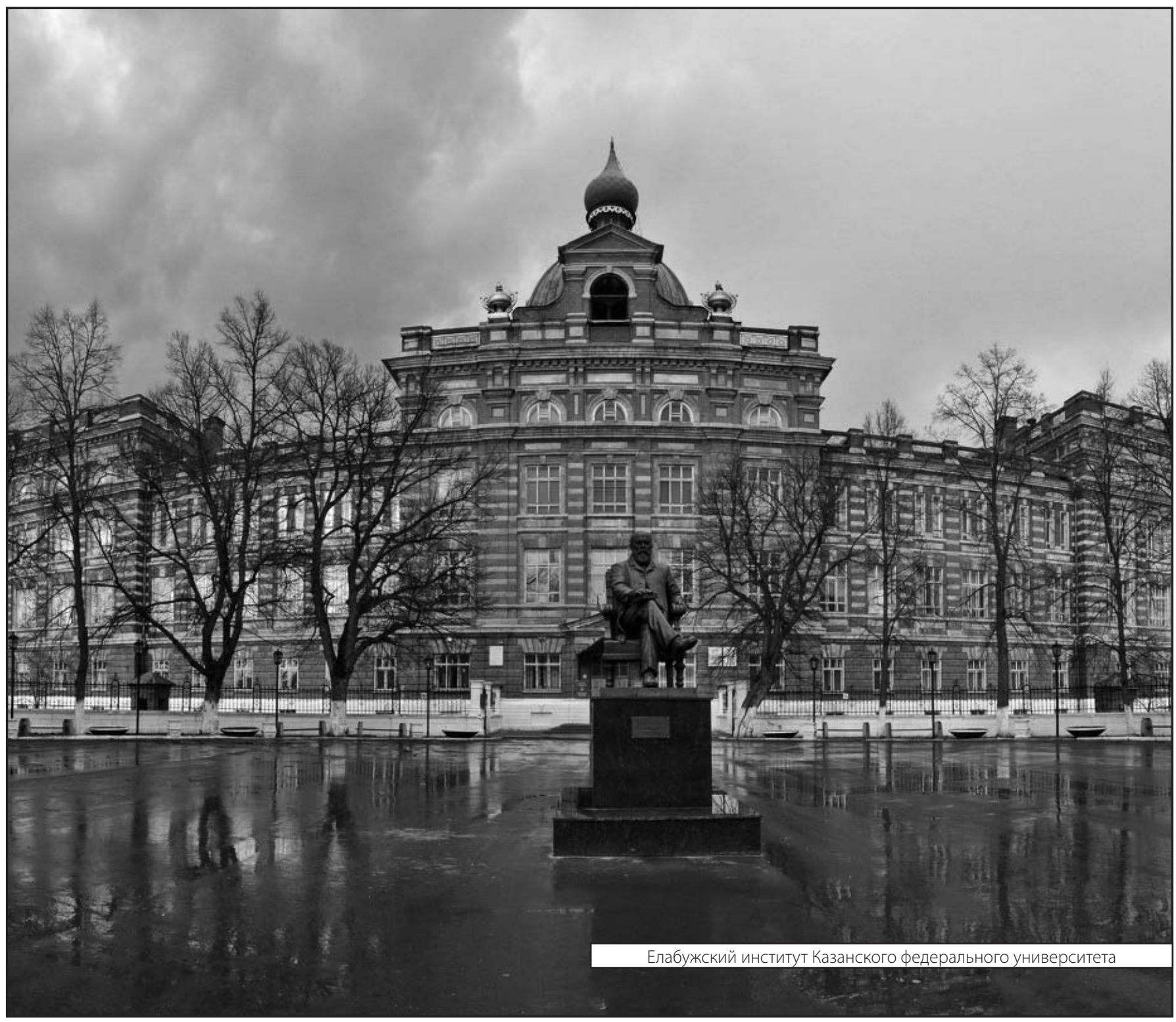

